\title{
miR-128 enhances dendritic cell-mediated anti-tumor immunity via targeting of p38
}

\author{
XUE LIANG $^{1,2 *}$, WENFENG SHANGGUAN ${ }^{1 *}$, MIAOMIAO ZHANG $^{2,3}$, \\ SHIYUE MEI ${ }^{2}$, LIYANG WANG ${ }^{4}$ and RONGCUN YANG ${ }^{2,5,6}$
}

\begin{abstract}
${ }^{1}$ Department of Cardiology, Tianjin Key Laboratory of Ionic-Molecular Function of Cardiovascular Disease, Tianjin Institute of Cardiology, Second Hospital of Tianjin Medical University, Tianjin 300211; ${ }^{2}$ State Key Laboratory of Medicinal Chemical Biology, School of Medicine, Nankai University, Tianjin 300071; ${ }^{3}$ School of Medicine, Jiangsu University, Zhenjiang, Jiangsu 212013, P.R. China; ${ }^{4}$ Faculty of Medicine, University of Southampton, Southampton, Hampshire SO17 1BJ, UK; ${ }^{5}$ Key Laboratory of Bioactive Materials Ministry of Education; ${ }^{6}$ Department of Immunology, Nankai University School of Medicine, Nankai University, Tianjin 300071, P.R. China
\end{abstract}

Received May 29, 2016; Accepted April 4, 2017

DOI: $10.3892 / \mathrm{mmr} .2017 .6717$

\begin{abstract}
MiRNA (miR)-128, which is a well-recognized inhibitor of tumor growth, is involved in the anti-tumor function of dendritic cells (DCs). However, the association between miR-128 and the DC-mediated anti-tumor immunity remains to be elucidated. Murine B16 melanoma cells and C57BL/6 male mice were used to obtain marrow-derived DCs. DCs were treated with B16 cell suspension. miR-128 mimic, miR-128 inhibitor, p38 inhibitor or negative control oligonucleotides were transfected into DCs. After transfection, mRNA and protein expression of p38 in DCs was detected via reverse transcription-quantitative polymerase chain reaction and western blotting. The present study demonstrated that the miR-128 abundance in DCs was significantly attenuated by B16 (a melanoma cell line) stimulation and the protein expression level of p38 was increased. Additionally, miR-128 inhibited the protein expression of p38 in DCs in a dose-dependent manner, however no significant effect on the p38 mRNA level was observed. Furthermore, miR-128 mimic or p38 inhibitor decreased the mRNA expression and secretion of interleukin (IL)-6 and IL-10 cytokines and increased the level of IL-12 in DCs, whereas an miR-128 inhibitor exhibited the opposite effects. These findings suggested that miR-128 regulated the immune response of DCs via p38-downstream cytokines. Furthermore, the tumor growth rate, size and weight were
\end{abstract}

Correspondence to: Dr Rongcun Yang, Department of Immunology, Nankai University School of Medicine, Nankai University, 94 Weijing Road, Tianjin 300071, P.R. China

E-mail: ryang@nankai.edu.cn

*Contributed equally

Key words: miRNA-128, p38, dendritic cell, anti-tumor, immunotherapy markedly decreased and the survival time prolonged, following injection of DCs harboring miR-128 mimic or p38 inhibitor in C57BL/6 mice bearing B16 melanoma. The results therefore suggest that miR-128 enhances the anti-tumor immunity response of DCs via targeting of the p38 mitogen activated protein kinase signaling pathway.

\section{Introduction}

Melanoma is the fastest-growing malignant tumor and therefore one of the most dangerous types of skin cancer. Globally, there were 232,000 newly diagnosed cases of melanoma and 55,000 estimated deaths in 2012 (1). The primary cause of melanoma is excessive exposure to ultraviolet light (UV), which leads to the uncontrollable growth of melanocytes. Early-stage melanoma may be treated via surgical resection. However, for patients with lymph node metastasis, radical lymph node dissection with adjuvant approaches including radiation, chemo, and immunotherapy are recommended (2). Radiotherapy may improve regional lymph node basin control however does not alter long-term survival (3), and chemotherapy drugs may induce adverse effects including neutropenia, neurotoxicity, fatigue, thrombocytopenia, delayed myelosuppression and gastrointestinal toxicities $(4,5)$. Melanoma is one of the most immunogenic types of cancer, therefore immunotherapy attempting to harness the immune system against tumors may potentially act as a successful curative in the future.

Dendritic cells (DCs), are effective antigen-presenting cells (APCs) that exist in the majority of human tumors and function to recognize, acquire and present antigens to naive T cells for the initiation of an antigen-specific adaptive immune response $(6,7)$. These properties result in the use of DCs as an ideal vaccine and immunotherapeutic strategy against cancers, as they are capable of capturing tumor antigens and presenting them to T cells in tumor-draining lymphoid tissues, which subsequently triggers the generation of tumor-specific cytotoxic T lymphocytes (CTLs) that reduce tumor mass (8). The efficacy of DC vaccines as the adjuvant treatment against 
metastatic melanoma has been explored in numerous clinical trials (9-13). However, tumors may exhibit the ability to escape immune recognition and rejection by inhibiting the maturation and differentiation of DCs which prevents the antigen presentation mediated by DCs (14). Therefore, attempts to manipulate DC signaling in order to create a defense against tumor-induced DC defects are required for the successful immunotherapy of cancer. It has been reported that regulation of the p38 mitogen activated protein kinase (MAPK) signaling pathway influences the differentiation of immature DCs and T cells $(15,16)$, and therefore p38 may act as an effective target to optimize the DC-mediated immunotherapy.

Multiple microRNAs (miRNAs, miRs) may regulate the expression of p38 and function in tumor growth, differentiation, apoptosis and metastasis. Lawson et al (17) previously demonstrated that $\mathrm{p} 38 \alpha$ is post-transcriptionally repressed by miR-128, which is a well-recognized tumor inhibitor (18-20) in HEK293 cells. However, the role of miR-128 in DC-mediated immunotherapy for melanoma has not yet been investigated. The present study analyzed the effect of miR-128 on p38 expression in DCs, and the curative effects of miR-128 and p38 were further assessed using a melanoma-bearing mouse model.

\section{Materials and methods}

Cell lines and animals. Murine B16 melanoma cells were purchased from American Type Culture Collection (ATCC; Manassas, VA, USA). A total of 80 C57BL/6 male mice (3-5 weeks, $20 \mathrm{~g}$ in weight), were obtained from the Academy of Military Science of Chinese people's Liberation Army (Beijing, China) and allocated into 12 cages, 5 mice per cage. All mice were allowed to acclimate for 1 week in a specific pathogen-free animal room at a temperature of $25^{\circ} \mathrm{C}$ and relative humidity of $60 \%$ prior to experiments. The artificial feed was sterilized by radioactive irradiation $\left({ }^{60} \mathrm{Co}\right)$ and provided daily, and the drinking water was filtered at level four and underwent ozone and ultraviolet disinfection. The light/dark cycles were $12 \mathrm{~h}$, from 7.30 am to $7.30 \mathrm{pm}$. All animal studies were approved by the Animal Care and Utilization Committee of the Second Hospital of Tianjin Medical University. (Tianjin, China).

Preparation and transfection of mouse bone marrow-derived $D C s$. The DCs used in the present study were derived from bone marrow cells $(21,22)$. Briefly, 4-week-old C57BL/6 mice were sacrificed by cervical dislocation. The femurs were dissected and each end of femurs cut off. The bone marrow was flushed out with RPMI-1640 (Nissui, Tokyo, Japan). Following centrifugation at $600 \mathrm{x}$ g for $10 \mathrm{~min}$ at $4^{\circ} \mathrm{C}$, cells were resuspended in $2 \mathrm{ml}$ ammonium chloride/potassium carbonate/EDTA (ACK buffer) and cultured at room temperature for $5 \mathrm{~min}$ to lyse red blood cells. Then, cells were washed in RPMI-1640 complete medium supplemented with $10 \%$ fetal bovine serum (FBS) and $100 \mathrm{U} / \mathrm{ml}$ penicillin and streptomycin (Gibco; Thermo Fisher Scientific, Inc., Waltham, MA, USA). Differentiation of progenitor cells to immature DCs was induced by culturing in media containing $10 \mathrm{ng} / \mathrm{ml}$ granulocyte/macrophage colony-stimulating factor (GM-CSF; BD Biosciences, San Jose, CA, USA) for 5-6 days.

MiR-128 mimic (5'-UCACAGUGA ACCGGUCUC UUU -3'), miR-128 inhibitor, p38 inhibitor or the negative
Table I. Primer sequences.

\begin{tabular}{ll}
\hline Primers & \multicolumn{1}{c}{ Sequence $\left(5^{\prime}-3^{\prime}\right)$} \\
\hline RT & \\
U6 & AACGCTTCACGAATTTGCGT \\
miR-128 & GTCGTATCCAGTGCAGGGTCCGA \\
& GGTATTCGCACTGGATACGACAAAGAG
\end{tabular}

\section{RT-qPCR}

U6

Forward

Reverse

CTCGCTTCGGCAGCACA

$\operatorname{miR}-128$

Forward

AACGCTTCACGAATTTGCGT

Reverse

GAPDH

Forward

Reverse

P38

Forward

GGCTCACAGTGAACCGG

GTGCAGGGTCCGAGGT

Reverse

IL-6

Forward

TGCACCACCAACTGCTTAG GATGCAGGGATGATGTTC

Reverse

CCTGATGATGAGCCTGTTGC GAGAAGGTCTTCCCCTCACA

IL-10

Forward TGGACTCCAGGACCTAGACA

Reverse GTCCCCAATGGAAACAGCTT

IL-12

$\begin{array}{ll}\text { Forward } & \text { CATCCTGTGTCACATTGACACTTGTG } \\ \text { Reverse } & \text { GCTTTGAGTCAAATCCAGAACATGC }\end{array}$

RT, reverse transcription; PCR, polymerase chain reaction; IL, interleukin; miR, miRNA.

control oligonucleotide were bought from Guangzhou RiboBio Co., Ltd. (Guangzhou, China). MiR-128 mimic, miR-128 inhibitor and p38 inhibitor were transfected into DCs using Entransfer $^{\mathrm{TM}}$-R-4000 (Engreen Biosystem Ltd., Beijing, China) according to the manufacturer's protocol, at concentrations of 50 and $100 \mathrm{~nm}$. The transfected cells were used for the following reverse transcription-quantitative polymerase chain reaction (RT-qPCR), western blotting and ELISA analyses.

Treatment of DCs with B16 cell suspension. B16 melanoma cells $\left(1 \times 10^{6}\right)$ were cultured in RPMI-1640 complete medium in 6 -well plates, and subsequently cultured in an incubator $\left(37^{\circ} \mathrm{C}\right.$, $5 \% \mathrm{CO}_{2}$ ). Cells at the logarithmic phase were harvested to extract the cell suspension. The mouse bone marrow-derived DCs were co-cultured with the suspension of B16 cells for $24 \mathrm{~h}$ at $37^{\circ} \mathrm{C}$. Then, the expression levels of miR-128, p38 mRNA and p38 protein in DCs were determined by using RT-qPCR and western blot analysis.

$R T-q P C R$. Total RNA was isolated from DCs using TRIzol ${ }^{\circledR}$ reagent (Invitrogen; Thermo Fisher Scientific, Inc.). A total 

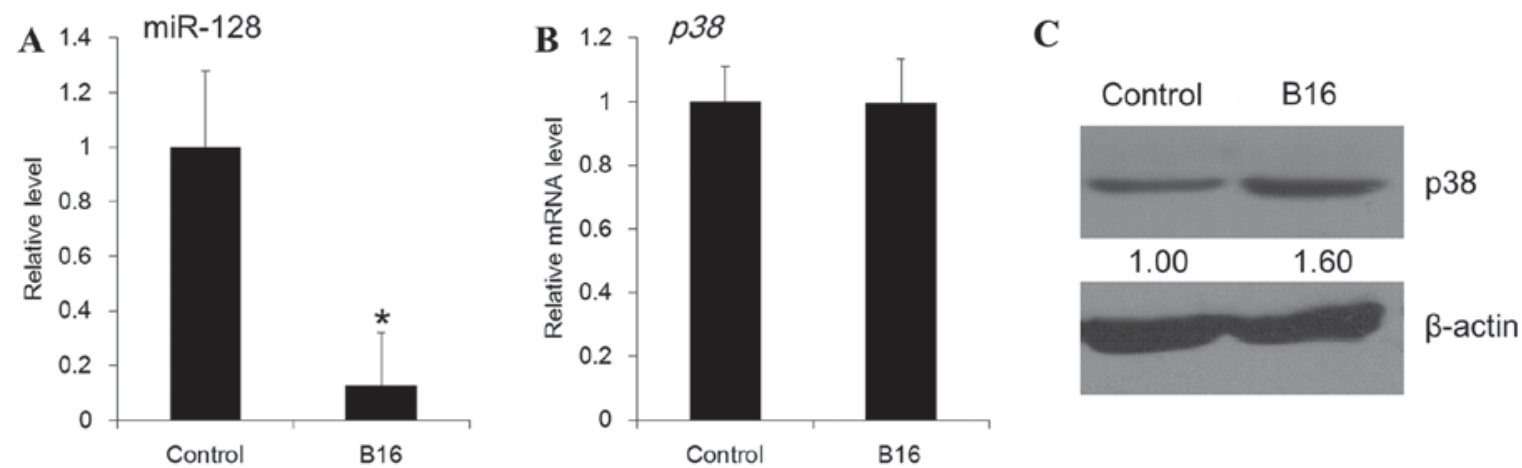

Figure 1. Expression of miR-128 and p38 levels in DCs as a response to B16 stimulation. (A) miR-128, (B) p38 mRNA and (C) p38 protein expression levels in DCs following B16 stimulation. Difference between two groups was analyzed by t-test. " $\mathrm{P}<0.05$ vs. control. miR, miRNA; DC, dendritic cells.

of $1 \mu \mathrm{g}$ RNA was added into the reverse transcription system containing M-MLV (Takara Biotechnology Co., Ltd., Dalian, China) according to the manufacturer's protocol. SYBR Green (Roche Applied Science, Penzberg, Germany) Real-time RT-qPCR was performed using an Applied Biosystems 7500 Fast Real-Time PCR System (Applied Biosystems; Thermo Fisher Scientific, Inc.) according to the following steps: denaturation at $94^{\circ} \mathrm{C}$ for $5 \mathrm{~min}$, followed by 40 amplification cycles of $94^{\circ} \mathrm{C}$ for $30 \mathrm{sec}, 55^{\circ} \mathrm{C}$ for $30 \mathrm{sec}$ and $72^{\circ} \mathrm{C}$ for $30 \mathrm{sec}$. Primers used for the PCR method are listed in Table I. Relative expression level of gene or miRNA was calculated using the $2^{-\Delta \Delta \mathrm{Cq}}$ method, where $\triangle \mathrm{Cq}$ means $\mathrm{Cq}$ (tested) $-\mathrm{Cq}_{\text {(internal control) }}$ (23). GAPDH and U6 were used as the internal control for genes and miRNAs, respectively.

Western blot analysis. Firstly, murine B16 melanoma cells were lysed using a lysis buffer (Beyotime Institute of Biotechnology, Haimen, China). Lysate concentration were measured using a Bradford assay. Following centrifugation at 4,800 x g for $5 \mathrm{~min}$ at $4^{\circ} \mathrm{C}$, the lysates were boiled in sodium dodecyl sulfate (SDS) loading buffer for $5 \mathrm{~min}$. Proteins $(50 \mu \mathrm{g})$ were separated by $10 \%$ SDS-PAGE, and then transferred to a polyvinylidene fluoride membrane (EMD Millipore, Billerica, MA, USA). The membrane was blocked with $5 \%$ Tris-buffered saline (TBS), $0.3 \%$ Tween-20,5\% non-fat milk for $2 \mathrm{~h}$ at $37^{\circ} \mathrm{C}$, and incubated at $4^{\circ} \mathrm{C}$ overnight with primary antibody of rabbit polyclonal anti-p38 (1:5,000; catalog no. 9212; Santa Cruz Biotechnology, Inc., Dallas, TX, USA).

Following washing with $0.1 \%$ Tween-TBS three times, the membrane was further incubated with the horseradish peroxidase conjugated secondary antibody goat anti-rabbit IgG-H\&L (1:10,000; catalog no. A21076, Bioworld Technology, Inc., St. Louis Park, MN, USA) for $1 \mathrm{~h}$ at $25^{\circ} \mathrm{C}$. Protein signals were visualized by using the enhanced chemiluminescence western blot detection system (EMD Millipore), and $\beta$-actin was used as the internal control.

ELISA. The transfected immature DC cells were stimulated with $1 \mu \mathrm{g} / \mathrm{ml}$ lipopolysaccharide (Sigma-Aldrich; Merck KGaA, Darmstadt, Germany) to induce activation and maturation. Cell supernatants were collected at 6, 12, 24 and $48 \mathrm{~h}$ time points and the secretion of cytokines including interleukin (IL)-6, -10 and -12 were measured using commercially available ELISA kits (catalog no. DY726; R\&D Systems, Inc., Minneapolis, MN, USA).
Animal model of melanoma. B16 melanoma cells were maintained under the aforementioned conditions. The cells were harvested by centrifugation at $600 \mathrm{x} \mathrm{g}$ for $5 \mathrm{~min}$, resuspended in PBS at a density of $1 \times 10^{6}$, and subcutaneously inoculated into the right flank of the C57BL/6 mice (100 $\mu \mathrm{l} / \mathrm{mice})$. The tumor growth of each mouse was monitored every 2 days. The model of melanoma was considered as successfully established if the tumor size was able to be measured on the 12th day following injection. Then, mice bearing B16 melanoma were randomly allocated into 5 groups, and there were 6 mice in each group: i) untreated, ii) negative control DCs treated, iii) miR-128 mimic treated, iv) miR-128 inhibitor treated and v) p38 treated groups. DCs harboring miR-128 mimic or inhibitor were injected intratumorally $\left(1 \times 10^{6} /\right.$ mice $)$ once every week. During this period, a subcutaneous Buprenorphine (Temgesic; $0.05 \mathrm{mg} / \mathrm{kg}$ ) treatment was applied to minimize the suffering of mice. The tumor size was determined every two days. The mice were sacrificed using the cervical dislocation method when the tumor size reached $3,000 \mathrm{~mm}^{3}$. Tumor volume was expressed as width ${ }^{2} \mathrm{x}$ length $\mathrm{x} \pi / 6$. Euthanasia was conducted if the mouse exhibited a moribund state including severe mobility loss, hunched back, piloerection, ruffled fur and weight loss. The survival time was defined as the period between tumor inoculation and this endpoint.

Statistical analysis. Data are expressed as the mean \pm standard deviation and were analyzed using SPSS software, version 19.0 (IBM SPSS, Armonk, NY, USA). Differences were analyzed using the unpaired Student's t-test for comparisons between two groups, and one-way analysis of variance followed by Bonferroni's multiple comparison test, for comparison among three or more groups. $\mathrm{P}<0.05$ was considered to indicate a statistically significant difference.

\section{Results}

miR-128 and p38 levels vary in DCs as a response to B16 stimulation. To explicate the roles of miR-128 and p38, the present study firstly determined the corresponding levels in DCs, as a response to B16 cells. Co-culturing with the B16 cell suspension resulted in a decreased level of miR-128 in the DCs $(\mathrm{P}=0.02$; Fig. 1A). In addition, the mRNA abundance of $p 38$ in DCs was not significantly altered following B16 stimulation $(\mathrm{P}=0.35$; Fig. 1B), whereas the p38 protein level was demonstrated to be increased (Fig. 1C). 
A
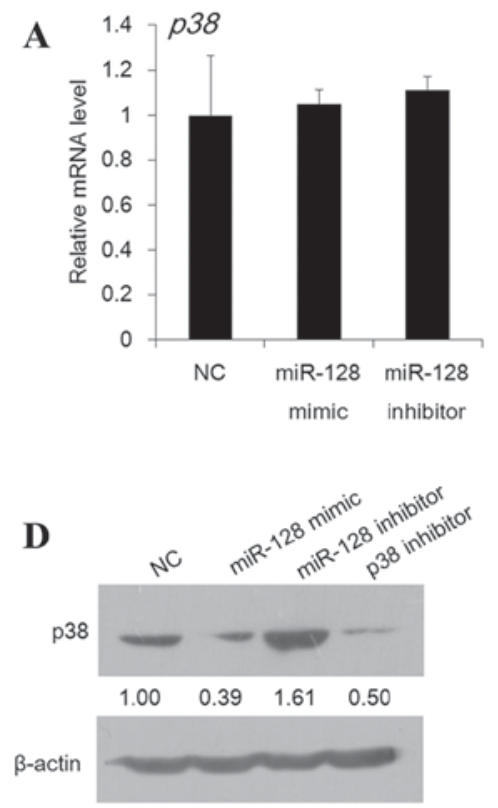

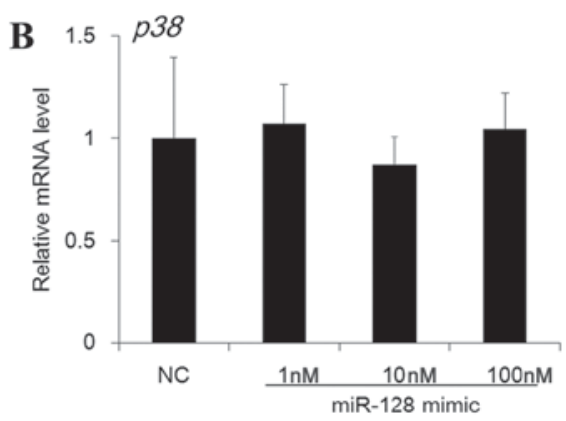

$\mathbf{E}$

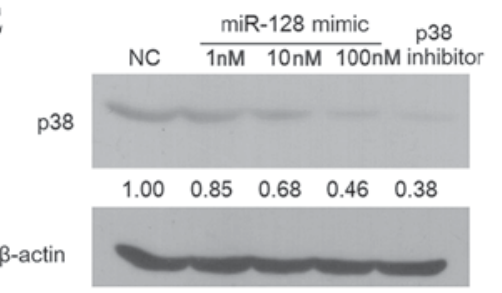

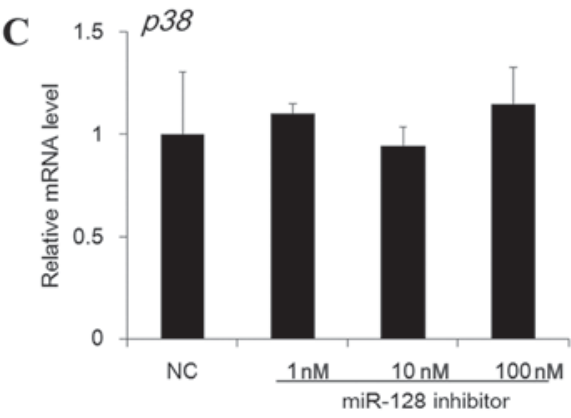

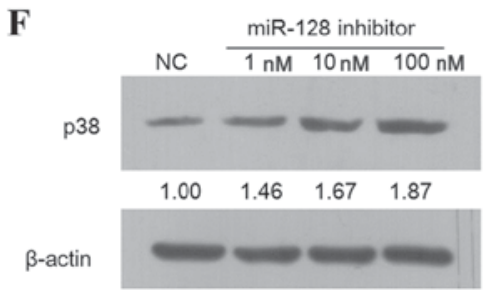

Figure 2. Effect of miR-128 on p38 expression levels in DCs. (A) Expression of $p 38$ gene was not significantly altered by miR-128 mimic or inhibitor in DCs. (B) Effects of differing doses of miR-128 mimic (1,10 or $100 \mathrm{nM}$ ) on $p 38$ gene expression. (C) Effects of differing doses of miR-128 inhibitor (1, 10 or $100 \mathrm{nM})$ on $p 38$ gene expression. (D) miR-128 mimic and inhibitor had markedly contrasting effects in the regulation of the expression of p38 protein. (E) Effects of differing doses of miR-128 mimic $(1,10$ or $100 \mathrm{nM})$ on p38 protein. miR-128 mimic demonstrated a dose-dependent effect on the inhibition of p38 protein. (F) Effects of differing doses of miR-128 inhibitor $(1,10$ or $100 \mathrm{nM})$ on p38 protein. p38 protein accumulation was enhanced by miR-128 inhibitor in a dose-dependent manner. Differences among groups were analyzed by one-way analysis of variance. NC, negative control dsRNA that did not target any gene; miR, miRNA; DC, dendritic cells.

miR-128 downregulates 38 protein level in DCs. The effect of miR-128 on $\mathrm{p} 38$ expression in DC cells was next assessed at the mRNA and protein level. As presented in Fig. 2A-C, no significant difference was observed in the $p 38$ mRNA abundance in DCs following treatment with miR-128 mimic or inhibitor at a dose of 1,10 or $100 \mathrm{nM}(\mathrm{P}>0.05)$. However, the protein expression of p38 was markedly suppressed by miR-128 mimic, whereas the miR-128 inhibitor enhanced the protein level (Fig. 2D). As presented in Fig. 2E and F, effects of the miR-128 mimic and inhibitor were observed to be exhibited in a dose dependent manner. These findings therefore demonstrated a post-transcriptional regulation of $p 38$ by miR-128.

miR-128 regulates the expression of cytokines in DCs. p38 has previously been demonstrated to be important in the regulation of the expression of cytokines $(24,25)$. miR-128 inhibited the p38 expression in DCs, therefore the present study further detected if the downstream cytokines of p38 were modulated by miR-128. As presented in Fig. 3, the gene expression and secretion levels of IL-6 and IL-10 were significantly suppressed by miR-128 mimic or p38 inhibitor, whereas the levels of IL-12 were increased $(\mathrm{P}<0.05)$. Conversely, the miR-128 inhibitor demonstrated the opposite effects $(\mathrm{P}<0.05)$. These data indicated that miR-12 regulated the expression of cytokines via inhibition of the p38 MAPK signaling pathway.

miR-128 enhances the anti-tumor effect of DCs. The present study then detected the influence of miR-128 and p38 on tumor growth in the $\mathrm{C} 57 \mathrm{BL} / 6$ mice bearing B16 melanoma. Injection of DCs harboring miR-128 mimic or p38 inhibitor significantly improved the therapeutic effect of DCs on melanoma, compared with the negative control DCs, which was reflected by retarded tumor growth, decreased tumor size and weight and a prolonged survival time $(\mathrm{P}<0.05 ;$ Fig. 4A-D). Conversely, the miR-128 inhibitor increased the tumor size and weight compared with the negative control ( $\mathrm{P}<0.05$; Fig. 4D).

\section{Discussion}

DC vaccines are currently the primary, investigational therapeutic approach against solid tumors. In the tumor environment, immature DCs have been revealed to accumulate whereas the functional mature DC total is decreased. The immature DCs are able to present tumor-derived antigens, however are unable to express co-stimulatory molecules, including cluster of differentiation (CD) 80 and CD86, adequate levels of major histocompatibility complex (MHC) molecules and appropriate cytokines that are required to active T cells (14). Therefore, the use of genetically modified DCs is of great research interest. The present study attempted to identify an improved immunotherapeutic strategy to target cancer, using DCs.

miRNAs are a class of non-coding RNAs that regulate genes by binding to their 3'-untranslated regions. Various miRNAs have previously been demonstrated to be important in the actions of the immune system. miR-128, a well-recognized tumor inhibitor, is capable of inhibiting Th2 differentiation and facilitating the Th1 response $(26,27)$, suggesting its potential application in immunosuppressive therapy. However, its role in DC-mediated anti-tumor immunity remains to be elucidated. In the present study, it was observed that the expression level of miR-128 was significantly decreased in DCs following stimulation with the supernatant of B16 cells. As DCs are recommended as immunotherapeutic strategy against cancer, 

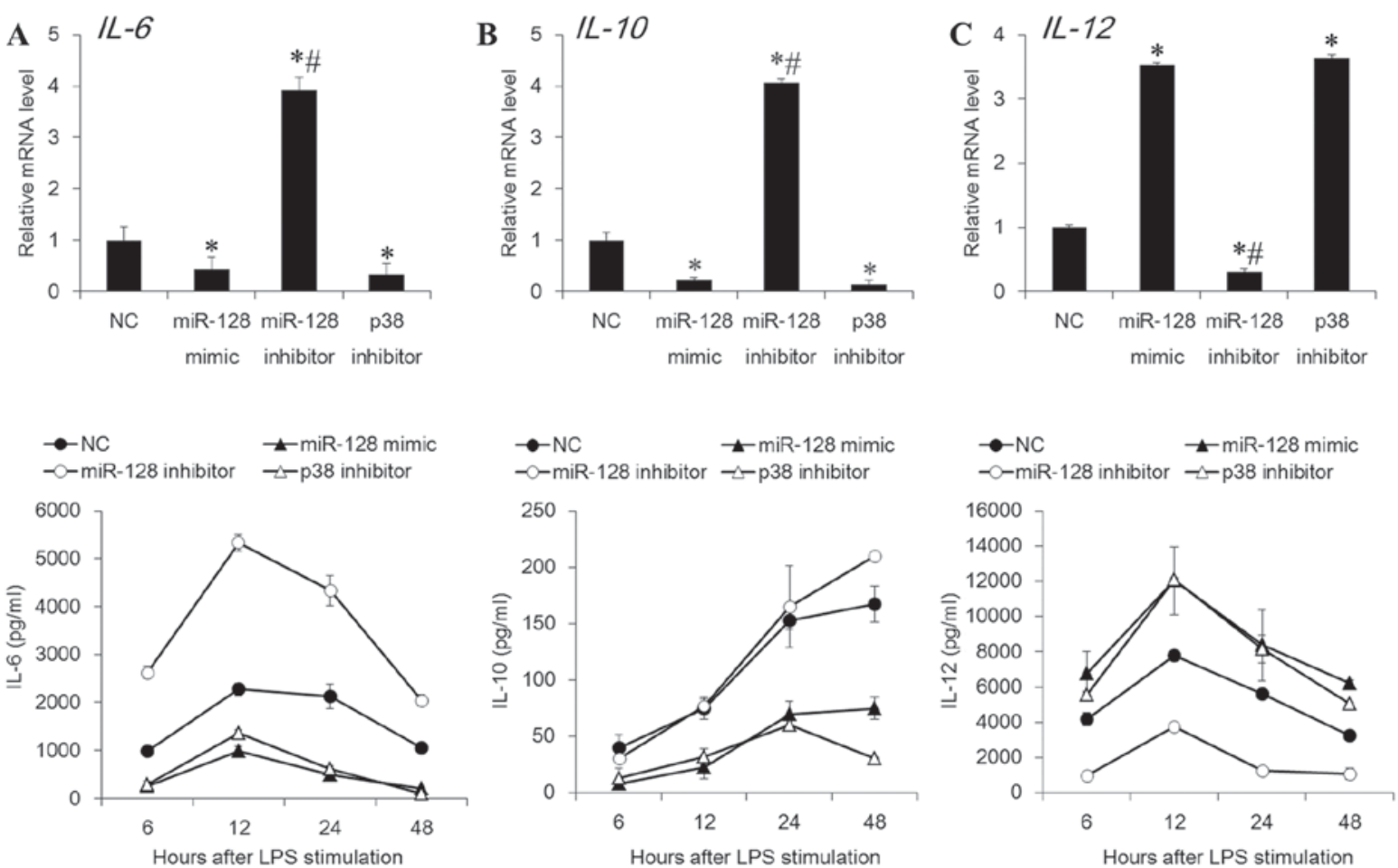

Figure 3. Effects of miR-128 and p38 on the mRNA and secretion levels of cytokines IL-6, -10 and -12 in DCs. The immature DCs were transfected with miR-128 mimic or inhibitor, or p38 inhibitor. Following this, cells were treated with lipopolysaccharide to promote the maturation of DCs. The mRNA expression of genes encoding (A) IL-6, (B) IL-10 and (C) IL-12 were detected via reverse transcription-quantitative polymerase chain reaction and the secretion levels were determined by ELISA during the $24 \mathrm{~h}$ treated time course. Differences among groups were analyzed by one-way analysis of variance, followed by Bonferroni's multiple comparison test. " $\mathrm{P}<0.05$ vs. control; " $\mathrm{P}<0.05$ vs. miR-128 mimic group. NC, negative control dsRNA that did not target any gene; miR, miRNA; DC, dendritic cells; IL, interleukin.

A

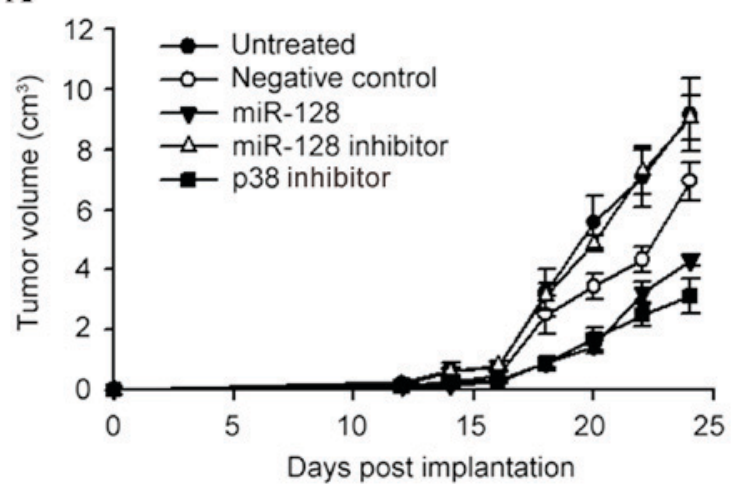

C

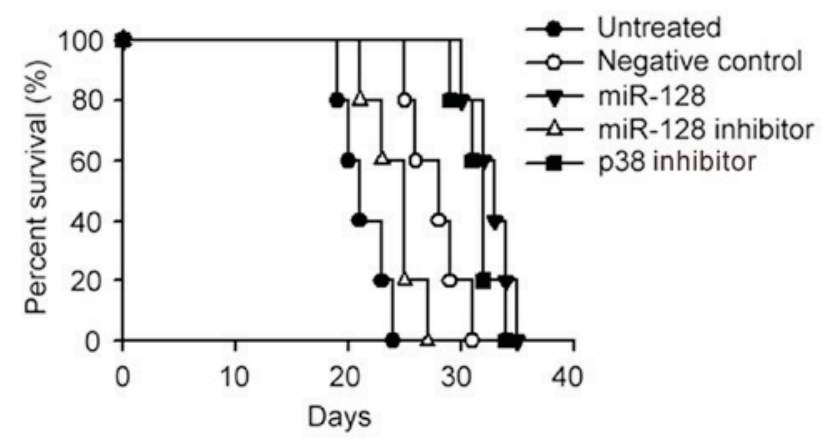

B
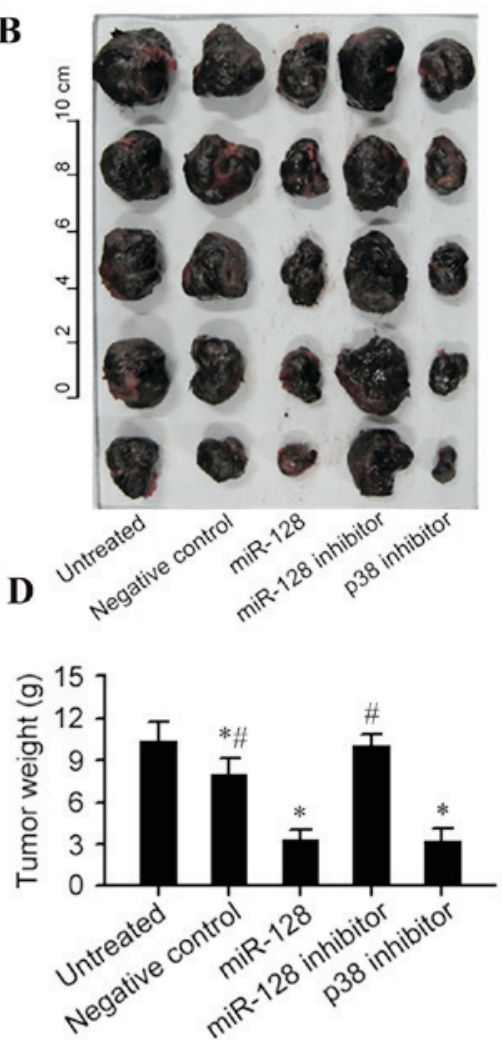

Figure 4. Role of miR-128 and p38 in the therapeutic effect of DCs. (A) Final tumor volume, (B) tumor growth plot, (C) animal survival time and (D) final tumor weight were assessed in C57BL/6 mice bearing B16 melanoma following injection with DCs harboring negative control oligonucleotide, miR-128 mimic or inhibitor, or p38 inhibitor. Differences among groups were analyzed by one-way analysis of variance, followed by Bonferroni's multiple comparison test. ${ }^{*} \mathrm{P}<0.05$ vs. control; ${ }^{\prime} \mathrm{P}<0.05$ vs. miR-128 mimic group. $\mathrm{NC}$, negative control dsRNA that did not target any gene; miR, miRNA; DC, dendritic cells. 
the alteration of miR-128 in DCs after B16 stimulation suggests that expression of miR-128 may be associated with an immune reaction in melanoma.

Furthermore, the miR-128 mimic or inhibitor was introduced into mouse bone marrow-derived DCs, and subsequently injected into mice bearing B16 melanoma. The results revealed that miR-128 induced objective tumor shrinkage and prolonged the survival time, verifying its previously established tumor inhibitory effect.

p38 is the target gene of miR-128, which was verified with the observation that miR-128 inhibited the protein level of p38 in DCs without affecting the mRNA abundance. In addition, the p38 protein expression levels were enhanced in DCs following B16 stimulation. Therefore, it was hypothesized that the miR-128/p38 regulation pattern may be important in the DC anti-tumor functionality. p38 exerts regulatory effects on cytokines which have pivotal effects on anti-tumor immunity, therefore the expression of genes encoding various cytokines and the secretion of these cytokines were tested following an introduction of miR-128 mimic, miR-128 inhibitor or p38 inhibitor into DCs. IL-6 may alter the differentiation route of monocytes to macrophages rather than DCs, which would block the priming of tumor-specific T cells by DCs (28). IL-6 additionally functions in maintaining immature DCs and obstructing the maturation of DCs via triggering the activation of signal transducer and activator of transcription (STAT) 3 (29), which underlines an inhibitory pathway of p38/IL-6/STAT3 in DC activation. In addition to IL-6, IL-10 is a critical cytokine blocking the maturation of DCs. By secreting the immunosuppressive cytokine IL-10, tumors may inhibit the maturation of DCs or convert DCs into macrophage-like cells $(30,31)$. Direct addition of anti-IL-10-neutralizing Ab to immature DCs, augments the expression of MHC and co-stimulatory molecules and the release of IL-12 (32). High expressions of MHC class II molecules and co-stimulatory molecules are associated with the maturation of DCs. The mature DCs have the ability to acquire $\mathrm{C}-\mathrm{C}$ motif chemokine receptor 7 that allows the migration of mature DCs into the draining lymph node $(33,34)$. Furthermore, the generated mature DCs acquire the ability to induce the differentiation of $\mathrm{CD} 4^{+}$and $\mathrm{CD} 8^{+}$ $\mathrm{T}$ cells into antigen-specific $\mathrm{T}$ cells, and therefore activate the CTL response to destroy the tumor cells (8). It has previously been demonstrated that DC cells derived from mice overexpressing IL-10 markedly restrain the T cell and CTL responses and IL-12 production (35). The results of the present study demonstrated that IL- 6 and IL-10 production were attenuated by miR-128 mimic and p38 inhibitor, whereas the IL-12 level was promoted. The miR-128 inhibitor demonstrated the opposite effect on the cytokine production levels. Jarnicki et al (36) suggests that inhibition of p38 signaling suppresses IL-10 and enhances IL-12 production in lipopolysaccharide-activated DCs, which increases the immunotherapeutic efficacy of DCs (36). Hence, combined with the fact that $p 38$ is the target of miR-128, the inhibitory effect of miR-128 overexpressed DCs on tumor growth may be attributed to the generation of appropriate cytokines.

In conclusion, the results of the present study suggested that miR-128 post-transcriptionally inhibited $\mathrm{p} 38$ expression in DCs and suppressed the downstream levels of cytokines secreted by DCs via decreasing the expression levels of their encoding genes, which consequently enhanced the anti-tumor immune response and inhibited tumor growth. The facilitation of DC-mediated anti-tumor immunity via miR-128 in the tumor microenvironment provides a novel strategy of immunotherapeutic value against various malignancies, including melanoma.

\section{Acknowledgements}

The present study was supported by the National Natural Science Foundation of China (grant nos. 31470876, 91029736 and 31200676), ISF-NSFC program (grant no. 31461143010), the Ministry of Science and Technology (863 program, grant no. 2008AA02Z129), the National Key Scientific Program (grant no. 2011CB964902), the Program for Changjiang Scholars and Innovative Research Team in University (grant no. IRT13023) and the China Postdoctoral Science Foundation funded project (grant no. 2015M571272).

\section{References}

1. Ferlay J, Soerjomataram I, Dikshit R, Eser S, Mathers C, Rebelo M, Parkin DM, Forman D and Bray F: Cancer incidence and mortality worldwide: Sources, methods and major patterns in GLOBOCAN 2012. Int J Cancer 136: E359-E386, 2015.

2. Guo J, Qin S, Liang J, Lin T, Si L, Chen X, Chi Z, Cui C, Du N, Fan Y, et al: Chinese guidelines on the diagnosis and treatment of melanoma (2015 Edition). Ann Transl Med 3: 322, 2015.

3. Henderson MA, Burmeister B, Ainslie J, Fisher R, Di Iulio J, Smithers BM, Hong A, Shannon KF, Scolyer RA, Carruthers S, et al: Adjuvant radiotherapy after lymphadenectomy in melanoma patients: Final results of an intergroup randomized trial (ANZMTG 0.1. 02/TROG 02.01). J Clin Oncol 31 (Suppl): S9001, 2013.

4. Walker L, Schalch H, King DM, Dietrich L, Eastman M, Kwak M, Kim K and Albertini MR: Phase II trial of weekly paclitaxel in patients with advanced melanoma. Melanoma Res 15: 453-459, 2005.

5. Avril MF, Aamdal S, Grob JJ, Hauschild A, Mohr P, Bonerandi JJ, Weichenthal M, Neuber K, Bieber T, Gilde K, et al: Fotemustine compared with dacarbazine in patients with disseminated malignant melanoma: A phase III study. J Clin Oncol 22: 1118-1125, 2004.

6. Steinman RM: Decisions about dendritic cells: Past, present, and future. Annu Rev Immunol 30: 1-22, 2012.

7. Banchereau J and Steinman RM: Dendritic cells and the control of immunity. Nature 392: 245-252, 1998.

8. Palucka K and Banchereau J: Cancer immunotherapy via dendritic cells. Nat Rev Cancer 12: 265-277, 2012.

9. Mackensen A, Herbst B, Chen JL, Köhler G, Noppen C, Herr W, Spagnoli GC, Cerundolo V and Lindemann A: Phase I study in melanoma patients of a vaccine with peptide-pulsed dendritic cells generated in vitro from CD34(+) hematopoietic progenitor cells. Int J Cancer 86: 385-392, 2000.

10. Nestle FO, Alijagic S, Gilliet M, Sun Y, Grabbe S, Dummer R, Burg G and Schadendorf D: Vaccination of melanoma patients with peptide- or tumor lysate-pulsed dendritic cells. Nat Med 4: 328-332, 1998.

11. Oshita C, Takikawa M, Kume A, Miyata H, Ashizawa T, Iizuka A, Kiyohara Y, Yoshikawa S, Tanosaki R, Yamazaki N, et al: Dendritic cell-based vaccination in metastatic melanoma patients: Phase II clinical trial. Oncol Rep 28: 1131-1138, 2012.

12. Engell-Noerregaard L, Hansen TH, Andersen MH, Thor Straten $P$ and Svane IM: Review of clinical studies on dendritic cell-based vaccination of patients with malignant melanoma: Assessment of correlation between clinical response and vaccine parameters. Cancer Immunol Immunother 58: 1-14, 2009.

13. Bol KF, Aarntzen EH, Hout FE, Schreibelt G, Creemers JH, Lesterhuis WJ, Gerritsen WR, Grunhagen DJ, Verhoef C, Punt CJ, et al: Favorable overall survival in stage III melanoma patients after adjuvant dendritic cell vaccination. Oncoimmunology 5: e1057673, 2016. 
14. Gabrilovich D: Mechanisms and functional significance of tumour-induced dendritic-cell defects. Nat Rev Immunol 4: 941-952, 2004.

15. Xie J, Qian J, Yang J, Wang S, Freeman ME III and Yi Q: Critical roles of Raf/MEK/ERK and PI3K/AKT signaling and inactivation of p38 MAP kinase in the differentiation and survival of monocyte-derived immature dendritic cells. Exp Hematol 33 564-572, 2005

16. Wang S, Hong S, Yang J, Qian J, Zhang X, Shpall E, Kwak LW and Yi Q: Optimizing immunotherapy in multiple myeloma: Restoring the function of patients' monocyte-derived dendritic cells by inhibiting p38 or activating MEK/ERK MAPK and neutralizing interleukin-6 in progenitor cells. Blood 108: 4071-4077, 2006.

17. Lawson SK, Dobrikova EY, Shveygert M and Gromeier M p38 a mitogen-activated protein kinase depletion and repression of signal transduction to translation machinery by miR-124 and -128 in neurons. Mol Cell Biol 33: 127-135, 2013.

18. Shi ZM, Wang J, Yan Z, You YP, Li CY, Qian X, Yin Y, Zhao P Wang YY, Wang XF, et al: MiR-128 inhibits tumor growth and angiogenesis by targeting p70S6K1. PLoS One 7: e32709, 2012.

19. Hu J, Cheng Y, Li Y, Jin Z, Pan Y, Liu G, Fu S, Zhang Y, Feng K and Feng Y: microRNA-128 plays a critical role in human non-small cell lung cancer tumourigenesis, angiogenesis and lymphangiogenesis by directly targeting vascular endothelial growth factor-C. Eur J Cancer 50: 2336-2350, 2014.

20. Li M, Fu W, Wo L, Shu X, Liu F and Li C: miR-128 and its target genes in tumorigenesis and metastasis. Exp Cell Res 319: 3059-3064, 2013.

21. Zhang Z, Liu Q, Che Y, Yuan X, Dai L, Zeng B, Jiao G, Zhang Y, Wu X, Yu Y, et al: Antigen presentation by dendritic cells in tumors is disrupted by altered metabolism that involves pyruvate kinase M2 and its interaction with SOCS3. Cancer Res 70: 89-98, 2010.

22. Min S, Liang X, Zhang M, Zhang Y, Mei S, Liu J, Su X, Cao S, Zhong X, Li Y, et al: Multiple tumor-associated microRNAs modulate the survival and longevity of dendritic cells by targeting YWHAZ and Bcl2 signaling pathways. J Immunol 190: 2437-2446, 2013

23. Livak KJ and Schmittgen TD: Analysis of relative gene expression data using real-time quantitative PCR and the 2(-Delta Delta C(T)) method. Methods 25: 402-408, 2001.

24. Anderson P: Post-transcriptional control of cytokine production. Nat Immunol 9: 353-359, 2008

25. Cargnello M and Roux PP: Activation and function of the MAPKs and their substrates, the MAPK-activated protein kinases. Microbiol Mol Biol Rev 75: 50-83, 2011.
26. Godlewski J, Nowicki MO, Bronisz A, Williams S, Otsuki A, Nuovo G, Raychaudhury A, Newton HB, Chiocca EA and Lawler S: Targeting of the Bmi-1 oncogene/stem cell renewal factor by microRNA-128 inhibits glioma proliferation and self-renewal. Cancer Res 68: 9125-9130, 2008.

27. Guerau-de-Arellano M, Smith KM, Godlewski J,Liu Y, Winger R, Lawler SE, Whitacre CC, Racke MK and Lovett-Racke AE: Micro-RNA dysregulation in multiple sclerosis favours pro-inflammatory T-cell-mediated autoimmunity. Brain 134: 3578-3589, 2011.

28. Chomarat P, Banchereau J, Davoust J and Palucka AK: IL-6 switches the differentiation of monocytes from dendritic cells to macrophages. Nat Immunol 1: 510-514, 2000.

29. Park SJ, Nakagawa T, Kitamura H, Atsumi T, Kamon H, Sawa S, Kamimura D, Ueda N, Iwakura Y, Ishihara K, et al: IL-6 regulates in vivo dendritic cell differentiation through STAT3 activation. J Immunol 173: 3844-3854, 2004.

30. McBride JM, Jung T, de Vries JE and Aversa G: IL-10 alters DC function via modulation of cell surface molecules resulting in impaired T-cell responses. Cell Immunol 215: 162-172, 2002.

31. Fortsch D, Röllinghoff M and Stenger S: IL-10 converts human dendritic cells into macrophage-like cells with increased antibacterial activity against virulent Mycobacterium tuberculosis. J Immunol 165: 978-987, 2000.

32. Corinti S, Albanesi C, la Sala A, Pastore S and Girolomoni G: Regulatory activity of autocrine IL-10 on dendritic cell functions. J Immunol 166: 4312-4318, 2001.

33. Trombetta ES and Mellman I: Cell biology of antigen processing in vitro and in vivo. Annu Rev Immunol 23: 975-1028, 2005.

34. Clatworthy MR, Aronin CE, Mathews RJ, Morgan NY, Smith KG and Germain RN: Immune complexes stimulate CCR7-dependent dendritic cell migration to lymph nodes. Nat Med 20: 1458-1463, 2014.

35. Sharma S, Stolina M, Lin Y, Gardner B, Miller PW, Kronenberg $M$ and Dubinett SM: T cell-derived IL-10 promotes lung cancer growth by suppressing both T cell and APC function. J Immunol 163: 5020-5028, 1999.

36. Jarnicki AG, Conroy H, Brereton C, Donnelly G, Toomey D, Walsh K, Sweeney C, Leavy O, Fletcher J, Lavelle EC, et al: Attenuating regulatory $\mathrm{T}$ cell induction by TLR agonists through inhibition of p38 MAPK signaling in dendritic cells enhances their efficacy as vaccine adjuvants and cancer immunotherapeutics. J Immunol 180: 3797-3806, 2008. 